\title{
The additional value of lung cancer screening program in identifying unrecognized diseases
}

\author{
Panaiotis Finamore ${ }^{1}$, Luigi Tanese ${ }^{2}$, Filippo Longo ${ }^{3^{*}} \mathbb{0}$, Domenico De Stefano ${ }^{2}$, Claudio Pedone ${ }^{1}$, \\ Laura Angelici ${ }^{4}$, Nera Agabiti ${ }^{4}$, Silvia Cascini ${ }^{4}$, Marina Davoli ${ }^{4}$, Bruno Beomonte Zobel ${ }^{2}$, \\ Raffaele Antonelli Incalzi ${ }^{1}$ and Pierfilippo Crucitti $^{3}$
}

\begin{abstract}
Background: A systematic examination of low-dose CT (LDCT) scan, beside lung nodules, may disclose the presence of undiagnosed diseases, improving the efficacy and the cost/efficacy of these programs. The study was aimed at evaluating the association between LDCT scan findings and non-oncologic and oncologic diseases.

Methods: The LDCT scan of participants to the "Un Respiro per la vita" ${ }^{\circledR}$ lung cancer screening program were checked and abnormal findings, beside lung nodules, recorded. First admission to the acute care because of cardiovascular (CD), respiratory (RD) and oncological diseases (OD) in the following three years were retrieved. The association of LDCT scan abnormal findings with $C D, R D$ and $O D$ was assessed through univariable and multivariable logistic regression models.
\end{abstract}

Results: Mean age of 746 participants was 62 years (SD:5), 62\% were male. 11 (1.5\%) received a diagnosis of lung cancer. $16.1 \%$ participants were admitted to the acute care in the following three years: $8.6 \%$ for CD, 4.3\% for RD and 5.2\% for OD. Valve calcification (OR 2.02, p:0.02) and mucus plugs (OR 3.37, p:0.04) were positively associated with CD, while sub-pleural fibrosis had a protective role (OR 0.47, p:0.01). Lung nodules $>8 \mathrm{~mm}$ (OR 5.54, p: $<0.01$ ), tracheal deviation (OR 6.04, p:0.01) and mucus plugs (OR 4.00, p:0.04) were positively associated with OD admissions. Centrilobular emphysema OR for RD admissions was 1.97 (p:0.06).

Conclusions: The observed association between selected LDCT findings and ensuing CD, RD and OD suggests that the information potential of LCDT goes beyond the screening of lung cancer.

Keywords: Computed tomography, Lung cancer, Screening, Cardiovascular disease, Respiratory disorders

\section{Background}

Annual screening for lung cancer in high risk populations through low dose computed tomography (LDCT) has gained popularity and is currently recommended by US Preventive Services Task Force (USPSTF) after the

\footnotetext{
*Correspondence: filippo.longo@unicampus.it

${ }^{3}$ Unit of Thoracic Surgery, Department of Medicine and Surgery, Campus

Bio-Medico University and Teaching Hospital, Rome, Italy
}

Full list of author information is available at the end of the article
National Lung Cancer Screening Trial (NLCST) could demonstrate a $20 \%$ decrease in lung cancer mortality in people aged $55-80$ years with a smoke history of at least 30 pack year, either current smokers or quitters from within 15 years $[1,2]$. Two smaller subsequent trials, the Danish Lung Cancer Screening Trial (DLCST) and the Detection and Screening of Early Lung Cancer by Novel Imaging Technology and Molecular Essays (DANTE), failed to confirm these favorable results [3, 4]. Indeed, in both trials the annual LDCT screening did not provide 
any survival benefit. Differences in the studied populations might partly account for discrepancy as a lower risk population was enrolled and a lower incidence of lung cancer was observed in both DLCST and DANTE trials. Selected differences in the definition of the suspicious lung nodule and in the follow up strategy are a further source of heterogeneity among the three studies. Interestingly, in all mentioned studies the low specificity of screening raised concern about the risk related to undue exposure to radiation and other unnecessary diagnostic procedures [2-4]. Also in the UKLS trial 1994 people had to be screened and then, to be exposed to radiation for 42 subjects being diagnosed with lung cancer. Secondary analyses of these trials showed that restricting the screening to higher risk people might be a convenient strategy to improve specificity [5]. Furthermore, an algorithm has been proposed to identify people most likely to benefit from lung cancer screening [6, 7]. Finally, in 2016 Katki et al. proposed a risk computation model and validated it in both the Prostate, Lung, Colorectal, and Ovarian Cancer Screening Trial (PLCO; 1993-2009) and the NLCST [8]. Such a model could avert a further $20 \%$ more deaths with regard to NLCST and spare an important proportion of unnecessary screenings. On the other hand, both the MILD trial and a meta-analysis of 4 trials failed to show any 5 year survival benefit of the screening procedure [9].

Data obtained through screening may be improved and refined by secondary analysis. For instance, the NELSON study convincingly demonstrated that new onset pulmonary nodules, i.e. nodules which were absent at baseline, carry a dismal prognosis and, as such, should be followed more aggressively [10]. Nevertheless, this useful information does not impact the basic limitation of any LDCT based screening procedure, the low specificity. Thus, the development of molecular biomarkers is eagerly awaited to improve the selection procedure, but to date the available biomarkers do not meet the required quality standards [11].

While the controversy about cost/efficacy of lung cancer screening will probably end with the joined elaboration of NELSON and UKLS data, we hypothesize that a more comprehensive and not exclusively oncologic approach to results from LDCT might disclose the full value of the screening. Indeed, there are many important non oncological conditions which might be disclosed by LDCT. Among those are lung fibrosis and bronchiectasis. Furthermore, non-pulmonary findings such as coronary artery calcium and vertebral density and structure might be a further valuable information from LDCT. Finally, selected LDCT features might herald lung cancer in subjects presently free from it. On these bases, as a proof of concept we planned to re-analyze comprehensively the first 1000 LDCT scans of people enrolled from April 2014 to May 2015 in the lung cancer screening program hosted in our Institution with the aim of catching the added non oncologic and oncologic value of the screening. Furthermore, we purposed to verify whether LDCT findings have prognostic and not only diagnostic potential towards cancer.

\section{Materials and methods}

\section{Study design and sources of data}

This is a secondary analysis of an ongoing mono-center and observational prospective study carried out at Campus Bio-Medico University and Teaching Hospital (CBM) in Rome, Italy. In this proof of concept study were consecutively included the first 1000 participants who performed a LDCT scan from April 2014 to May 2015, and their admission to the acute care in the following three years for cardiovascular, respiratory and oncological disease (CD, RD, OD) was investigated. Standardized record linkage procedures using a unique code identifier were applied to link clinical datasets with the regional population registry (PR) that comprised the place of residence and dates of health insurance coverage for all enrollees of the Lazio Regional Health Service. Death certificates from the regional mortality register were used to update the PR. All data sources can be linked between them using anonymous key according to the national privacy law (national legislative decree on privacy policy n. 196/30 June 2003). The Regional Health Information System databases (ICD-9-CM codes of the International Classification of Diseases) was used to identify the outcomes. The Department of Epidemiology of Lazio Regional Health Service is the regional referral center for epidemiological research and has full access to anonymized health information systems. This study conforms to the principles outlined in the Declaration of Helsinki and it was approved by the Ethical Commission of the Campus Bio-Medico University (protocol:34/15 PAR ComEt CBM). All the study participants provided written informed consent.

\section{Setting}

"Un Respiro per la Vita" ${ }^{\circledR}$ (Breath for Life) is a lung cancer screening program funded by "Fondazione Un Respiro per la Vita Onlus ${ }^{\circledR}$ " which offers, free of charge, the opportunity to perform a LDCT scan to eligible candidates, i.e. people aged 55-75 years deemed at risk for developing lung cancer given their smoking history (current smokers or quitters from within10 years), exposure to carcinogens (e.g. asbestos, radiation, etc.) or history of chronic obstructive pulmonary disease (COPD). Exclusion criteria are: current oxygen therapy and history of cancer, apart from localized prostatic cancer, in situ 
uterine cervix cancer and non-melanoma skin cancer, in the previous five years. Candidates underwent a preliminary outpatient visit where a multidisciplinary team evaluates eligibility criteria and collects socio-demographic information. Then, participants performed a LDCT scan. LDCT was preferred to CT scan to reduce radiationinduced damages, as recommended by the European Respiratory Society and the American Thoracic Society $[12,13]$. A description of the management of positive findings, defined as nodule equal or larger than $5 \mathrm{~mm}$, is out of the aim of the present study and can be found elsewhere [14, 15]. For the purposes of the present study we will limit the analysis to people enrolled according to standard criteria $[2,16]$, but data pertaining to the whole enrolled population will also be provided.

\section{Low dose CT-scan}

LDCT scans were performed from the lung apices to bases in a single breath hold at $120 \mathrm{kVp}, 30 \mathrm{~mA}, 1.4: 1$ pitch ratio. The axial images were collimated at $0.6 \mathrm{~mm}$ and reconstructed at $3 \mathrm{~mm}$ slice thickness, using both the bone and soft tissue algorithms. No intravenous contrast material was administrated. All CT examinations were performed using a 64-detector row CT scanner (Siemens Somatom Sensation, Erlangen). Two radiologists involved in the study, with 5 years of experience in chest CT scan interpretation, were instructed to report respiratory findings (lung, bronchial tree or pleural alterations), beside the identification of lung nodules, cardiovascular findings and other findings (e.g. breast nodules, hiatal hernia). A detailed list of LDCT considered findings can be found in Additional file 1 (see $e$-Table 1). Where was impossible to perform a quantitative evaluation to establish the effective presence of a radiological finding, a quality assessment was already made. The radiologist readers coded such findings as "present" (score 1) or "absent" (score 0) in a double-blind mode.

\section{Outcome assessment}

The incidence of the first event of an acute hospitalization was retrieved from the Regional HIS. Hospital electronic records of participants up to three years from the enrollment were reviewed to ascertain the incidence of acute admission for cardiovascular $(C D)$, respiratory (RD) or oncological disease (OD). First hospital CD admission was defined on the basis of main diagnosed ICD9CM codes: "Cardiovascular Disease" (codes 390-409, 415-425 and 439-459); "Coronary Heart Disease, Ischemic Cardiomyopathy" (codes 410-414, 429.7); "Arrhythmias" (codes 426, 427), "Hypertension" (codes 401-405), "Heart failure" (code 428) and "Cerebrovascular Disease" (codes 430, 432-438). First hospital RD admission was defined as on the basis of main diagnosis ICD9CM codes 460-519,
Table 1 Participants' characteristics and LDCT scan findings $(n=746)$

\begin{tabular}{|c|c|}
\hline Variables & $N=746$ \\
\hline \multicolumn{2}{|l|}{ Age (years) } \\
\hline $52-58$ & $203(27.2)$ \\
\hline $59-64$ & $306(41.0)$ \\
\hline $65-78$ & $237(31.8)$ \\
\hline $\operatorname{Sex}(M)$ & $462(61.9)$ \\
\hline Smokers & $540(72.4)$ \\
\hline Ex-smokers & $206(27.8)$ \\
\hline Pack year & $49.5(19.9)$ \\
\hline Professional exposure & $2(0.27)$ \\
\hline Cancer pathology familiarity & $359(48.1)$ \\
\hline \multicolumn{2}{|l|}{ Comorbidities } \\
\hline Asthma & $12(1.6)$ \\
\hline Diabetes mellitus & $57(7.6)$ \\
\hline Hypertension & $260(34.9)$ \\
\hline Gastroesophageal reflux disease & $34(4.6)$ \\
\hline Hypercholesterolemia & $136(18.2)$ \\
\hline Hyperthyroidism & $1(0.1)$ \\
\hline Benign prostatic hyperplasia (BPH) & $47(6.3)$ \\
\hline \multicolumn{2}{|l|}{ Lung nodules } \\
\hline Nodules $<=4 \mathrm{~mm}$ & $174(23.3)$ \\
\hline Nodules 5-6 mm & $135(18.1)$ \\
\hline Nodules 7-8 mm & $43(5.8)$ \\
\hline Nodules $>=8 \mathrm{~mm}$ & $98(13.1)$ \\
\hline \multicolumn{2}{|l|}{ LDCT findings } \\
\hline Ground glass opacity & $47(6.3)$ \\
\hline Centrilobular emphysema & $227(30.4)$ \\
\hline Paraseptal emphysema & $82(11)$ \\
\hline Atelectasis areas & $68(9.1)$ \\
\hline Bronchial wall thickening & 291 (39) \\
\hline Bronchiectasis & $62(8.3)$ \\
\hline Diffuse fibrosis & $14(1.9)$ \\
\hline Subpleural fibrosis & $277(37.1)$ \\
\hline Paravertebral fibrosis & $25(3.4)$ \\
\hline Mucus plugs & $17(2.3)$ \\
\hline Tracheal deviation & $18(2.4)$ \\
\hline Focal pleural thickening & $58(7.8)$ \\
\hline Pleural effusion & $0(0)$ \\
\hline Vascular Calcifications & $356(47.7)$ \\
\hline Coronary Calcifications & $276(37)$ \\
\hline Valve Calcifications & $119(16)$ \\
\hline Breast nodule & $12(1.6)$ \\
\hline
\end{tabular}

Categorical variables are expressed as frequency (\%), while continuous variables as mean (SD)

involving acute and chronic respiratory diseases (e.g. pneumonia, COPD). Finally, first hospital OD admission was defined on the basis of main diagnosis ICD9CM codes 140-208.9 and V10, thus not limited to lung cancer. 


\section{Statistical analysis}

Data were reported using mean and standard deviations (SD) or median and interquartile range (IQR) for continuous variables, and number and percentage (\%) for categorical variables. In order to make our results comparable with those of previous lung cancer screening trials, we focused our main analyses to the individuals who performed LDCT scans because of their smoking history ( $n=746)$, excluding those eligible by exposure to carcinogens and by history of COPD $(n=228)$. However, results of the analyses performed on the whole screened sample with available follow up are reported in supplemental material (see Additional file 1: e-Table S2, e-Table S3, e-Table S4 and e-Table S5). The inter-rater reliability of radiologists was assessed using the Cohen's kappa. The association of LDCT scan findings (exposure variables) and the incidence of CD, RD and OD acute hospitalization (outcomes) was assessed using logistic regression in a crude model and after adjusting for age, sex and pack year, considered as potential confounders. All the analyses were performed using the Statistical Analysis System (SAS) statistical software package, version 9.4. SAS Institute Inc., Cary, NC, USA.

\section{Results}

\section{Participants}

A total of 1000 individuals entered the lung cancer screening program between April 2014 to May 2015: 974 (97.6\%) had available data in the Lazio Region PR. The $74.7 \%(n=746)$ was eligible because of the smoking history according to criteria shared by the vast majority of such trials and, thus, was the primary object of our study (see Fig. 1). The remaining 25.3\% $(n=228)$ was enrolled due to professional exposure or a history of COPD. Participants had a mean age of 62 years (SD:5), 62\% were male and $72 \%$ were current smokers; mean pack year was 49.5 (SD: 19.9). Table 1 summarize participants' characteristics and LDCT findings.

\section{Inter rater agreement}

The kappa Cohen's coefficient disclosed a good to high concordance between raters (kappa $\geq 0.50, \mathrm{p}<0.001)$ for the vast majority of the LDCT scan findings of interest. The only findings for which the agreement did not reach this threshold were: mucus plugs and thickening of bronchial tree. A detailed list of kappa coefficients for individual findings of interest is reported in Additional file 1: e-Table S6.

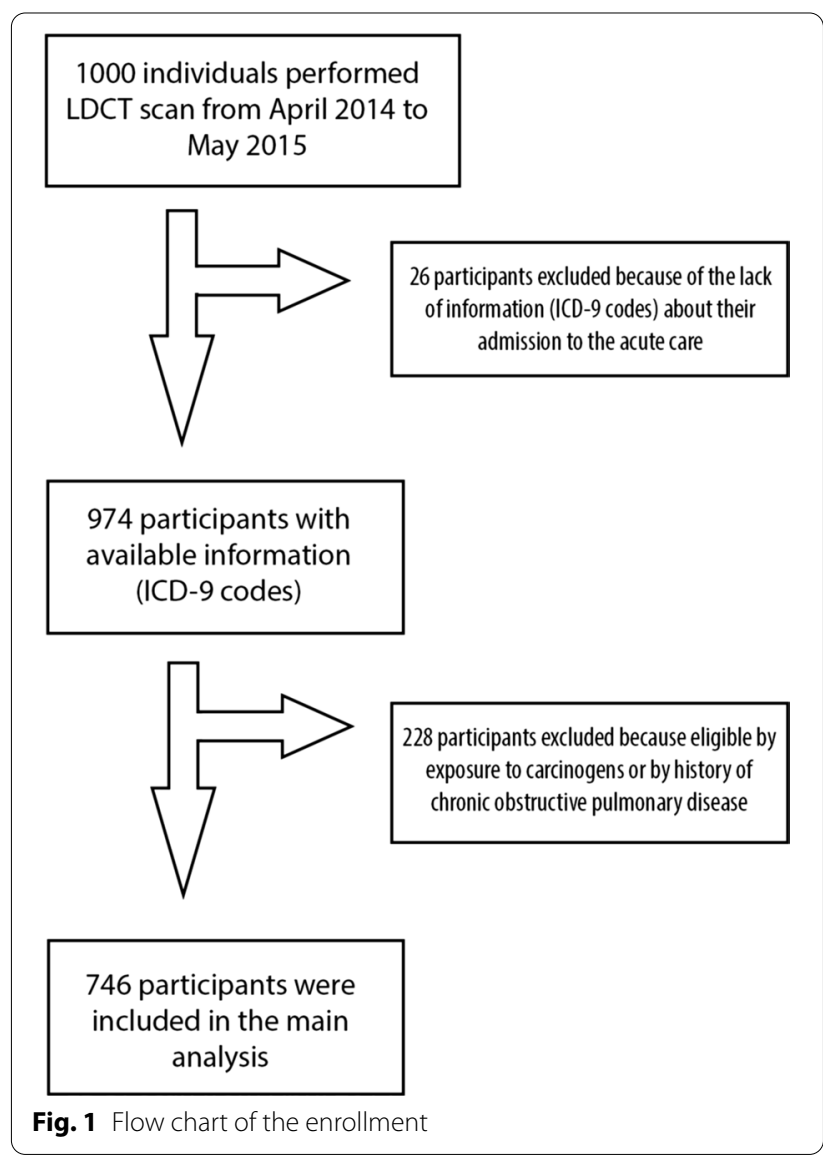

\section{Lung cancer screening}

276 (37\%) participants had a positive finding at LDCT scan, $174(23.3 \%)$ had nodule/s lower than $5 \mathrm{~mm}$ and 296 (39.7\%) were completely free from nodules. 14 (1.9\%) screened individuals were addressed to biopsy. $11(1.5 \%)$ were positive for primitive lung cancer: 10 (91\%) were adenocarcinoma and 1 (9\%) was squamous cell lung cancer. Of the 7 patients with lung cancer who underwent surgery in our Institution, 4 were in stage Ia-Ib.

\section{Occurrence of $C D, R D$ and $O D$ admissions}

During the follow-up, 120 (16.1\%) participants were admitted to the acute care: 64 (8.6\%) for CD, 32 (4.3\%) for RD and 39 (5.2\%) for OD. Among OD admissions, 16 (41\%) were for lung cancer and 23 (59\%) for other oncologic diseases, mainly breast cancer (6 participants) and genitourinary cancer (5 participants). Of the 16 patients admitted for lung cancer, 11 were those already diagnosed at baseline and 5 were new diagnoses in patients addressed to follow-up for their lung nodules. The median time to the occurrence was 479 days for $\mathrm{CD}, 467$ for RD and 353 for OD. 


\section{Association of LDCT scan findings and outcomes}

Mucus plugs (OR 3.37, 95\%CI 1.04-10.89, p 0.04) and valve (OR 2.02, 95\% CI 1.11-3.67, p 0.02), but not coronary (OR 1.56, 95\%CI 0.91-2.66, p 0.10), calcifications were positively associated with $\mathrm{CD}$ admissions in the adjusted model, while subpleural fibrosis showed a negative association (OR 0.47, 95\%CI 0.26-0.86, p 0.01) (see Table 2).

Emphysema, mainly when centrilobular, was associated with RD admissions in the univariable, but not in the adjusted model (OR 1.97, 95\%CI 0.96-4.05, p 0.06) (see Table 3). However, when considering a composite outcome of neoplastic and non-neoplastic respiratory disease centrilobular emphysema showed a positive association (OR 2.00, 95\% CI 1.10-3.63, p 0.02).

Lung nodules $>8 \mathrm{~mm}$ (OR 5.54, 95\%CI 2.45-12.54, $\mathrm{p}<0.01$ ), tracheal deviation (OR 6.04, 95\%CI 1.49-24.4, p 0.01) and mucus plugs (OR 4.00, 95\%CI 1.05-15.18, p
0.04) showed a positive associations with OD admissions (see Table 4).

With the exception of the positive association of RD admissions with centrilobular (OR 2.12, 95\%CI 1.13$3.97, \mathrm{p} 0.02$ ) and paraseptal emphysema (OR 2.69, 95\% CI 1.26-5.74, p 0.01), the associations between LDCT scan findings and outcomes did not change with the inclusion of the 228 individuals who entered the screening program because of the exposure to carcinogens or as affected by COPD (see Additional file 1: e-Table S 2, e-Table S 3, e-Table S 4 and e-Table S 5).

A positive association was found between age, male sex (OR 2.13, 95\%CI 1.17-3.87, p 0.01), smoking habit (smoker vs quitter OR 1.93, 95\%CI 0.99-3.77, p 0.05) and cumulative smoking exposure (pack year: OR 1.01, 95\%CI 1.00-1.02, p 0.05) with CD admissions, although the last two associations were not statistically significant. No association was instead found between age, sex

Table 2 Association between participants' characteristics and LDCT scan findings with cardiovascular diseases $(n=64)$

\begin{tabular}{|c|c|c|c|c|c|c|c|}
\hline & \multirow[b]{2}{*}{$N=64$} & \multicolumn{3}{|c|}{ Univariable logistic regression } & \multicolumn{3}{|c|}{ Multivariable logistic regression } \\
\hline & & OR & $95 \% \mathrm{Cl}$ & $\mathbf{P}$ & OR & $95 \% \mathrm{Cl}$ & $\mathbf{P}$ \\
\hline \multicolumn{8}{|l|}{ Age } \\
\hline $52-58$ years & $10(15.6)$ & Ref & & & - & - & - \\
\hline $59-64$ years & $30(46.9)$ & 2.10 & $1.00-4.39$ & 0.05 & - & - & - \\
\hline $65-78$ years & $24(37.5)$ & 2.18 & $1.01-4.66$ & 0.05 & - & - & - \\
\hline Sex (M) & 49 (76.6) & 2.13 & $1.17-3.87$ & 0.01 & - & - & - \\
\hline \multicolumn{8}{|l|}{ Smoking } \\
\hline Former smoker & $11(17.2)$ & Ref & & & - & - & - \\
\hline Current smoker & $53(82.8)$ & 1.93 & $0.99-3.77$ & 0.05 & - & - & - \\
\hline Pack year & 49 (19.7) & 1.01 & $1.00-1.02$ & 0.05 & - & - & - \\
\hline \multicolumn{8}{|l|}{ Lung nodules } \\
\hline No nodules & $24(37.5)$ & Ref & & & Ref & & \\
\hline Nodules $<=8 \mathrm{~mm}$ & $33(51.6)$ & 1.13 & $0.64-2.00$ & 0.68 & 1.11 & $0.62-1.97$ & 0.73 \\
\hline Nodules $>8 \mathrm{~mm}$ & $7(10.9)$ & 1.05 & $0.51-2.17$ & 0.89 & 0.96 & $0.46-1.99$ & 0.46 \\
\hline Ground glass opacity & $4(6.3)$ & 0.99 & $0.34-2.85$ & 0.99 & 1.10 & $0.38-3.21$ & 0.38 \\
\hline Centrolobular emphysema & $20(31.3)$ & 1.04 & $0.60-1.81$ & 0.88 & 0.96 & $0.55-1.68$ & 0.87 \\
\hline Paraseptal emphysema & $9(14.1)$ & 1.37 & $0.65-2.88$ & 0.41 & 1.22 & $0.57-2.59$ & 0.61 \\
\hline Atelectasis areas & $6(9.4)$ & 1.04 & $0.43-2.50$ & 0.94 & 1.01 & $0.41-2.45$ & 0.99 \\
\hline Bronchial wall thickening & $30(46.9)$ & 1.42 & $0.85-2.38$ & 0.18 & 1.33 & $0.79-2.24$ & 0.28 \\
\hline Bronchiectasis & $6(9.4)$ & 1.16 & $0.48-2.80$ & 0.75 & 1.14 & $0.47-2.79$ & 0.77 \\
\hline Diffuse fibrosis & $3(4.7)$ & 3.00 & $0.82-11.04$ & 0.10 & 2.49 & $0.65-9.51$ & 0.18 \\
\hline Subpleural fibrosis & $15(23.4)$ & 0.49 & $0.27-0.89$ & 0.02 & 0.47 & $0.26-0.86$ & 0.01 \\
\hline Paravertebral fibrosis & $4(6.3)$ & 2.10 & $0.70-6.31$ & 0.19 & 1.90 & $0.62-5.83$ & 0.26 \\
\hline Mucus plugs & $4(6.3)$ & 3.43 & $1.08-10.83$ & 0.04 & 3.37 & $1.04-10.89$ & 0.04 \\
\hline Tracheal deviation & $1(1.6)$ & 0.63 & $0.08-4.84$ & 0.66 & 0.45 & $0.06-3.55$ & 0.45 \\
\hline Coronary calcifications & $33(51.6)$ & 1.92 & $1.15-3.22$ & 0.01 & 1.56 & $0.91-2.66$ & 0.10 \\
\hline Valve calcifications & $18(28.1)$ & 2.25 & $1.26-4.04$ & $<0.01$ & 2.02 & $1.11-3.67$ & 0.02 \\
\hline Breast nodule & $2(3.1)$ & 2.17 & $0.47-10.12$ & 0.32 & 3.33 & $0.67-16.66$ & 0.14 \\
\hline
\end{tabular}

Categorical variables are expressed as frequency (\%), while continuous variables as mean (SD). Adjustment variables in the multivariable logistic regression were age, sex and pack year. Broncholitiasis was not represented in this cohort 
Table 3 Association between participants' characteristics and LDCT scan findings with respiratory diseases $(n=32)$

\begin{tabular}{|c|c|c|c|c|c|c|c|}
\hline & \multirow[b]{2}{*}{$\mathrm{N}=32$} & \multicolumn{3}{|c|}{ Univariable logistic regression } & \multicolumn{3}{|c|}{ Multivariable logistic regression } \\
\hline & & OR & $95 \% \mathrm{Cl}$ & $\mathbf{P}$ & OR & $95 \% \mathrm{Cl}$ & $\mathbf{P}$ \\
\hline \multicolumn{8}{|l|}{ Age } \\
\hline $52-58$ years & $7(21.9)$ & Ref & & & - & - & - \\
\hline 59-64 years & $13(40.6)$ & 1.24 & $0.49-3.17$ & 0.65 & - & - & - \\
\hline $65-78$ years & $12(37.5)$ & 1.49 & $0.58-3.87$ & 0.41 & - & - & - \\
\hline Sex (M) & $25(78.1)$ & 2.26 & $0.97-5.30$ & 0.06 & - & - & - \\
\hline \multicolumn{8}{|l|}{ Smoking } \\
\hline Former smoker & $8(25)$ & Ref & & & - & - & - \\
\hline Current smoker & $24(75)$ & 1.15 & $0.51-2.61$ & 0.73 & - & - & - \\
\hline Pack year & $49.2(19.7)$ & 1.01 & $1.00-1.03$ & 0.05 & - & - & - \\
\hline \multicolumn{8}{|l|}{ Lung nodules } \\
\hline No nodules & $12(37.5)$ & Ref & & & Ref & & \\
\hline Nodules $<=8 \mathrm{~mm}$ & $11(34.4)$ & 0.76 & $0.33-1.76$ & 0.53 & 0.77 & $0.33-1.78$ & 0.54 \\
\hline Nodules $>8 \mathrm{~mm}$ & $9(28.1)$ & 2.39 & $0.98-5.87$ & 0.06 & 2.11 & $0.85-5.24$ & 0.11 \\
\hline Ground glass opacity & $1(3.13)$ & 0.47 & $0.06-3.51$ & 0.46 & 0.51 & $0.07-3.83$ & 0.51 \\
\hline Centrilobular emphysema & $15(46.9)$ & 2.09 & $1.03-4.26$ & 0.04 & 1.97 & $0.96-4.05$ & 0.06 \\
\hline Paraseptal emphysema & $7(21.9)$ & 2.39 & $1.00-5.70$ & 0.05 & 2.10 & $0.87-5.07$ & 0.10 \\
\hline Atelectasis areas & $3(9.4)$ & 1.03 & $0.31-3.48$ & 0.96 & 1.02 & $0.30-3.48$ & 0.97 \\
\hline Bronchial wall thickening & $11(34.4)$ & 0.81 & $0.39-1.71$ & 0.96 & 0.75 & $0.35-1.59$ & 0.45 \\
\hline Bronchiectasis & $1(3.1)$ & 0.35 & $0.05-2.57$ & 0.30 & 0.34 & $0.05-2.56$ & 0.29 \\
\hline Diffuse fibrosis & $2(6.3)$ & 3.90 & $0.84-18.21$ & 0.08 & 3.16 & $0.65-15.51$ & 0.16 \\
\hline Subpleural fibrosis & $11(34.4)$ & 0.88 & $0.42-1.86$ & 0.74 & 0.86 & $0.40-1.82$ & 0.69 \\
\hline Paravertebral fibrosis & $1(3.1)$ & 1.04 & $0.12-7.08$ & 0.94 & 0.81 & $0.11-6.31$ & 0.84 \\
\hline Mucus plugs & $1(3.1)$ & 1.41 & $0.18-10.94$ & 0.74 & 1.40 & $0.18-11.03$ & 0.75 \\
\hline Coronary calcifications & $16(50)$ & 1.75 & $0.86-3.55$ & 0.12 & 1.45 & $0.69-3.03$ & 0.33 \\
\hline Valve calcifications & $5(15.6)$ & 0.98 & $0.37-2.58$ & 0.96 & 0.86 & $0.32-2.32$ & 0.76 \\
\hline Breast nodule & $1(3.1)$ & 2.06 & $0.26-16.48$ & 0.49 & 3.54 & 0.40 & 0.25 \\
\hline
\end{tabular}

Categorical variables are expressed as frequency (\%), while continuous variables as mean (SD). Adjustment variables in the multivariable logistic regression were age, sex and pack year. The following LDCT scan findings were not represented in this cohort: bronchiolitis, bronchiolitiasis, tracheal deviation, pulmonary trunk ectasia, pericardium pouring, thoracic cage abnormalities and hiatal hernia

and smoking habit with RD admissions, albeit a positive association, even not statistically significant, was found between pack year and RD admissions (OR 1.01, 95\%CI $1.00-1.03$, p 0.05). Furthermore, age and smoking habit and cumulative exposure did not show any association with OD admissions, while a negative and significant association was found between male sex (OR $0.51,95 \% \mathrm{CI}$ 0.26-0.97, p 0.04) and OD admissions.

\section{Discussion}

Our analysis shows that selected LDCT scan findings in variable proportion qualify as harbingers of cardiovascular, respiratory and oncologic diseases, as identified on the basis of related acute care admissions in the three years following the LDCT scan screening. Thus, besides identifying eleven subjects amenable to surgery for early stage lung cancer, LDCT scan provided an additional information which seems worthy of being carefully assessed.
Mucous plugs were the main predictors of cardiovascular events, despite being very rare. Indeed, 4 out of the 17 subjects having mucous plugs had a cardiovascular event. Thus, the fact that this pulmonary finding reflecting inflammation predicted a cardiovascular outcome suggests that systemic inflammation as a spill over of pulmonary inflammation promotes atherosclerosis and related diseases. This is on line with a bulk of basic $[17,18]$ and clinical [19] research findings, and with the evidence in the whole screened sample that bronchiectasis has a positive association with $\mathrm{CD}$ (see e-Table 3). Interestingly, valve calcifications, but not vascular calcifications, were cardiovascular findings associated with a cardiovascular outcome. Valve calcifications are commonly expression of valve degeneration in older population [20]. Once considered to be the result of a passive process, nowadays they are ascribed to endothelial dysfunction and inflammation promoting the extracellular matrix remodelling, and eventually the bone deposition leading 
Table 4 Association between participants' characteristics and LDCT scan findings with oncologic diseases $(n=39)$

\begin{tabular}{|c|c|c|c|c|c|c|c|}
\hline & \multirow[b]{2}{*}{$N=39$} & \multicolumn{3}{|c|}{ Univariable logistic regression } & \multicolumn{3}{|c|}{ Multivariable logistic regression } \\
\hline & & OR & $95 \% \mathrm{Cl}$ & $\mathbf{P}$ & OR & $95 \% \mathrm{Cl}$ & $\mathbf{P}$ \\
\hline \multicolumn{8}{|l|}{ Age } \\
\hline $52-58$ years & $7(18)$ & Ref & & & - & - & - \\
\hline $59-64$ years & $14(35.9)$ & 1.34 & $0.53-3.38$ & 0.53 & - & - & - \\
\hline $65-78$ years & $18(46.1)$ & 2.30 & $0.94-5.62$ & 0.07 & - & - & - \\
\hline Sex (M) & $18(46.1)$ & 0.51 & $0.26-0.97$ & 0.04 & - & - & - \\
\hline \multicolumn{8}{|l|}{ Smoking } \\
\hline Former smoker & $7(18)$ & Ref & & & - & - & - \\
\hline Current smoker & $32(82)$ & 1.79 & $0.78-4.12$ & 0.17 & - & - & - \\
\hline Pack year & $52.4(27.6)$ & 1.01 & $0.99-1.02$ & 0.33 & - & - & - \\
\hline \multicolumn{8}{|l|}{ Lung nodules } \\
\hline No nodules & $11(28.2)$ & Ref & & & Ref & & \\
\hline Nodules $<=8 \mathrm{~mm}$ & $11(28.2)$ & 0.84 & $0.36-1.96$ & 0.68 & 0.77 & $0.33-1.82$ & 0.55 \\
\hline Nodules $>8$ mm & $17(43.6)$ & 5.44 & $2.45-12$ & $<0.01$ & 5.54 & $2.45-12.54$ & $<0.01$ \\
\hline Ground glass opacity & $3(7.7)$ & 1.25 & $0.37-4.24$ & 0.71 & 1.12 & $0.33-3.83$ & 0.86 \\
\hline Centrilobular emphysema & $14(35.9)$ & 1.30 & $0.66-2.55$ & 0.45 & 1.34 & $0.67-2.67$ & 0.40 \\
\hline Paraseptal emphysema & $6(15.4)$ & 1.51 & $0.61-3.72$ & 0.37 & 1.49 & $0.59-3.73$ & 0.40 \\
\hline Atelectasis areas & $6(15.4)$ & 1.89 & $0.76-4.69$ & 0.17 & 1.92 & $0.76-4.84$ & 0.17 \\
\hline Bronchial wall thickening & $18(46.1)$ & 1.36 & $0.71-2.60$ & 0.35 & 1.25 & $0.64-2.42$ & 0.51 \\
\hline Bronchiectasis & $3(7.7)$ & 0.91 & $0.27-3.06$ & 0.88 & 0.78 & $0.23-2.65$ & 0.69 \\
\hline Subpleural fibrosis & $14(35.9)$ & 0.94 & $0.48-1.85$ & 0.87 & 0.88 & $0.45-1.73$ & 0.71 \\
\hline Paravertebral fibrosis & $2(5.1)$ & 1.61 & $0.36-7.08$ & 0.53 & 1.56 & $0.35-6.95$ & 0.56 \\
\hline Mucus plugs & $3(7.7)$ & 4.12 & $1.13-14.99$ & 0.03 & 4 & $1.05-15.18$ & 0.04 \\
\hline Tracheal deviation & $3(7.7)$ & 4.58 & $1.23-17$ & 0.02 & 6.04 & $1.49-24.4$ & 0.01 \\
\hline Coronary calcifications & $17(43.6)$ & 1.34 & $0.7-2.56$ & 0.38 & 1.39 & $0.70-2.76$ & 0.35 \\
\hline Valve calcifications & $8(20.5)$ & 1.38 & $0.62-3.09$ & 0.43 & 1.21 & $0.53-2.77$ & 0.64 \\
\hline Breast nodule & $1(2.6)$ & 1.66 & $0.21-13.23$ & 0.63 & 1.04 & $0.12-8.58$ & 0.12 \\
\hline
\end{tabular}

Categorical variables are expressed as frequency (\%), while continuous variables as mean (SD). Adjustment variables in the multivariable logistic regression were age, sex and pack year. The following LDCT scan findings were not represented in this cohort: diffuse fibrosis, pulmonary trunk ectasia, pericardium pouring and thoracic cage abnormalities

to valve calcification [21]. This interpretation strengthens the hypothesis that inflammation underpins the association between valve calcification and $\mathrm{CD}$ occurrence. Furthermore, the negative association between subpleural fibrosis and CD is rather than intuitive. Subpleural fibrosis likely represents the effect of pneumonia, metapneumonic fibrosis. Since patients who experience an important pneumonia likely are more motivated to quit smoking, this seems the most likely explanation of the protective role of subpleural fibrosis.

Emphysema was associated with respiratory non neoplastic events, mainly pneumonia $[n=8(1.1 \%)]$ and exacerbated COPD [ $n=22(2.3 \%)]$. Structural abnormalities of the lung are expected to correlate mainly with manifestations of chronic respiratory conditions like COPD rather than with pneumonia, however smoke exposure and lung damage are also related to impaired organ immunity and, then, to the risk of respiratory infections $[22,23]$. Furthermore, mucus plugs were not associated with RD. Since hospital admissions are the largest determinant of the direct medical costs related to COPD exacerbations [24], only severe cases are hospitalized, and the same is for pneumonia, therefore the lack of association might at least in part depend on the underestimation of the RD occurrence.

The detection rate of the screening program was $0.011 \%$, and raised to $0.016 \%$ considering the 5 participants who received the diagnosis of lung cancer during the follow-up. However, considering the identification of other types of cancer (e.g. breast cancer) among participants addressed to follow-up for their nodules, the detection rate of this screening is even higher, and may further increase including individuals with an exposure to carcinogens and with COPD who are more likely to develop cancer. Associated with an incident OD were nodules exceeding $8 \mathrm{~mm}$, which is not surprising, and also tracheal deviation and mucus plugs. Tracheal deviation usually reflects advanced lung cancer, but this is 
not the case since the maximum diameter of the nodules was $\leq 4 \mathrm{~cm}$. Thus, it might be a chance finding or reflect the occurrence of tracheal deviations as an effect of asymmetrical emphysema or fibrosis, which are well known risk factors for cancer. Indeed, only $5 \%$ of tracheal deviations were not associated with a shift of the mediastinum due to emphysema, bronchiectasis or other chronic lung abnormalities. Finally, mucus plugs might represent the epiphenomenon of chronic lung inflammation, which represent a widely recognized risk factor for lung and non-lung cancers [25, 26], or be the expression of advanced lung disease, which likely explains their association with OD.

\section{Strength and limitations}

Limitations of this study are many. First, the outcome was a proxy outcome; likely it does not cover the full spectrum of events. However, the well standardized computation method guarantees for these data defining a true, albeit somehow incomplete, outcome. Second, the concordance between readers varied across the different LDCT scan findings, ranging from $0.26(95 \% \mathrm{CI}$ $0.15-0.67)$ for mucus plugs to 0.92 (95\%CI $0.77-1.07$ ) for paraseptal emphysema (see e-Table 6). This variability, though in a range consistent with fine to good agreement for almost all the considered LDCT scan findings, might partly affect the strength of the associations. However, it seemed logical to discuss them because a proof of concept study like this requires a liberal approach while waiting for a larger validation study. Finally, the available information prevented us from testing selected hypotheses to explain the observed correlations.

\section{Conclusion}

Though preliminary and obtained on a small population, these data highlight the potential of LDCT based lung cancer screening for identifying patients at greater risk of CD and RD besides OD. They show that selected LDCT findings have multiple prognostic properties in a population with smoking exposure over the threshold for screening eligibility, and, thus, are worthy of being carefully searched for and recorded. However, targeting people at risk of $\mathrm{CD}, \mathrm{RD}$ or OD does not automatically mean that such a strategy is cost/effective. Indeed, it is worthy of confirmation in larger population and for different degree on inter observer agreement as for LDCT findings of interest. Thus, only the definitive production of predictive models and the formal computation of their diagnostic accuracy will allow define the true value of these preliminary, yet intriguing, observations.
Abbreviations

LDCT scan: Low-dose CT scan; CD: Cardiovascular diseases; RD: Respiratory diseases; OD: Oncological diseases.

\section{Supplementary Information}

The online version contains supplementary material available at https://doi. org/10.1186/s12890-022-01826-1.

Additional file 1. It provides a detailed description of LDCT scan findings (e-Table 1), and their association with CD (e-Table 3), RD (e-Table 4) and OD (e-Table 5) in the whole sample of 974 screened patients (e-Table $\mathbf{2}$ ). e-Table 6 reports the radiologists' agreement per LDCT finding.

Acknowledgements

Not applicable.

Authors' contributions

CP, RAI, BBZ, PC, LA and NA participated in the study concept and design, LT, DDS, SC, FL and PF collected the data, LA, NA and MD performed data analysis, LT, DDS, SC FL and PF interpreted the data, FL and PF wrote the draft. All the Authors substantively revised the final version of the manuscript and gave their consent to publication.

Funding

"Respiro per la Vita"(B) (Breath for Life) is funded by Fondazione Un Respiro per la Vita Onlus ${ }^{\circledR}$. The sponsor had no role in the design, analysis and interpretation of the data and had no role in the manuscript writing.

\section{Availability of data and materials}

Data related to the findings reported in our manuscript are available from the corresponding author to all interested researchers upon reasonable request and with the permission of the Regional Department, because of stringent legal restrictions regarding the privacy policy on personal in-formation in Italy (national legislative decree on privacy policy n. 196/30 June 2003). For these reasons our dataset cannot be made available on public data deposition.

\section{Declarations}

\section{Ethics approval and consent to participate}

The study was approved by the Ethical Commission of the Campus BioMedico University (protocol:34/15 PAR ComEt CBM). All the study participants provided written informed consent. Data at follow-up were collected by The Department of Epidemiology of the Lazio Regional Health Service, the regional referral centre for epidemiological research, that has full access to anonymized health information systems and Regional Dialysis and Transplant Registry granted by the Regional Council (DGR 152/2014).

\section{Consent for publication}

All the study participants provided written informed consent to participate. This study does not include participants'images or video and participants' details are entirely unidentifiable, thus no consent for publication was required.

\section{Competing interests}

Authors have no financial and non-financial competing interests to declare.

\section{Author details}

${ }^{1}$ Unit of Geriatrics, Department of Medicine and Surgery, Campus Bio-Medico University and Teaching Hospital, Rome, Italy. ${ }^{2}$ Unit of Imaging Center, Department of Medicine and Surgery, Campus Bio-Medico University and Teaching Hospital, Rome, Italy. ${ }^{3}$ Unit of Thoracic Surgery, Department of Medicine and Surgery, Campus Bio-Medico University and Teaching Hospital, Rome, Italy. ${ }^{4}$ Dipartimento di Epidemiologia del Servizio Sanitario Regionale, Regione Lazio, ASL Roma 1, Rome, Italy.

Received: 19 August 2021 Accepted: 18 December 2021

Published online: 31 January 2022 


\section{References}

1. US Preventive Services Task Force, Krist AH, Davidson KW, Mangione CM, Barry MJ, Cabana M, et al. Screening for lung cancer: US preventive services task force recommendation statement. JAMA. 2021;325:962-70.

2. National Lung Screening Trial Research Team, Aberle DR, Adams AM, Berg CD, Black WC, Clapp JD, et al. Reduced lung-cancer mortality with low-dose computed tomographic screening. N Engl J Med. 2011;365:395-409.

3. Wille MMW, Dirksen A, Ashraf H, Saghir Z, Bach KS, Brodersen J, et al. Results of the randomized Danish lung cancer screening trial with focus on high-risk profiling. Am J Respir Crit Care Med. 2016;193:542-51.

4. Infante M, Cavuto S, Lutman FR, Passera E, Chiarenza M, Chiesa G, et al. Long-term follow-up results of the DANTE trial, a randomized study of lung cancer screening with spiral computed tomography. Am J Respir Crit Care Med. 2015;191:1166-75.

5. Field JK, Duffy SW, Baldwin DR, Brain KE, Devaraj A, Eisen T, et al. The UK Lung Cancer Screening Trial: a pilot randomised controlled trial of lowdose computed tomography screening for the early detection of lung cancer. Health Technol Assess Winch Engl. 2016;20:1-146.

6. Tammemägi MC, Katki HA, Hocking WG, Church TR, Caporaso N, Kvale PA, et al. Selection criteria for lung-cancer screening. N Engl J Med. 2013;368:728-36.

7. Tammemägi MC, Church TR, Hocking WG, Silvestri GA, Kvale PA, Riley $T L$, et al. Evaluation of the lung cancer risks at which to screen ever- and never-smokers: screening rules applied to the PLCO and NLST cohorts. PLoS Med. 2014;11:e1001764.

8. Katki HA, Kovalchik SA, Berg CD, Cheung LC, Chaturvedi AK. Development and validation of risk models to select ever-smokers for CT lung cancer screening. JAMA. 2016;315:2300-11.

9. Pastorino U, Rossi M, Rosato V, Marchianò A, Sverzellati N, Morosi C, et al. Annual or biennial CT screening versus observation in heavy smokers: 5-year results of the MILD trial. Eur J Cancer Prev Off J Eur Cancer Prev Organ ECP. 2012;21:308-15.

10. Walter JE, Heuvelmans MA, de Jong PA, Vliegenthart R, van Ooijen PMA, Peters RB, et al. Occurrence and lung cancer probability of new solid nodules at incidence screening with low-dose CT: analysis of data from the randomised, controlled NELSON trial. Lancet Oncol. 2016;17:907-16.

11. Mazzone PJ, Sears CR, Arenberg DA, Gaga M, Gould MK, Massion PP, et al. Evaluating molecular biomarkers for the early detection of lung cancer: when is a biomarker ready for clinical use? An official American thoracic society policy statement. Am J Respir Crit Care Med. 2017;196:e15-29.

12. Kauczor H-U, Baird A-M, Blum TG, Bonomo L, Bostantzoglou C, Burghuber $\mathrm{O}$, et al. ESR/ERS statement paper on lung cancer screening. Eur Respir J. 2020;55.

13. Tanoue LT, Tanner NT, Gould MK, Silvestri GA. Lung cancer screening. Am J Respir Crit Care Med. 2015;191:19-33.

14. Rocco R, Incalzi RA, Pennazza G, Santonico M, Pedone C, Bartoli IR, et al. BIONOTE e-nose technology may reduce false positives in lung cancer screening programmest. Eur J Cardio-Thorac Surg Off J Eur Assoc CardioThorac Surg. 2016;49:1112-7; discussion 1117.

15. Mangiameli G, Longo F, Grasso RF, lacopino A, Rocco R, Quintarelli F, et al. Focus on lung cancer screening program at Campus Bio-Medico of Rome: update on over 3250 patients. Minerva Chir. 2017:72:361-3.

16. National Lung Screening Trial Research Team, Aberle DR, Berg CD, Black WC, Church TR, Fagerstrom RM, et al. The National Lung Screening Trial: overview and study design. Radiology. 2011;258:243-53.

17. Wang H, Hou L, Kwak D, Fassett J, Xu X, Chen A, et al. Increasing regulatory $T$ cells with interleukin-2 and interleukin-2 antibody complexes attenuates lung inflammation and heart failure progression. Hypertens Dallas Tex. 1979:2016(68):114-22.

18. Wouters EFM. Local and systemic inflammation in chronic obstructive pulmonary disease. Proc Am Thorac Soc. 2005;2:26-33.

19. Calverley PMA, Scott S. Is airway inflammation in chronic obstructive pulmonary disease (COPD) a risk factor for cardiovascular events? COPD. 2006;3:233-42.

20. Nkomo VT, Gardin JM, Skelton TN, Gottdiener JS, Scott CG, EnriquezSarano M. Burden of valvular heart diseases: a population-based study. Lancet Lond Engl. 2006;368:1005-11.

21. Conte M, Petraglia L, Campana P, Gerundo G, Caruso A, Grimaldi MG, et al. The role of inflammation and metabolic risk factors in the pathogenesis of calcific aortic valve stenosis. Aging Clin Exp Res. 2021;33:1765-70.
22. Strzelak A, Ratajczak A, Adamiec A, Feleszko W. Tobacco smoke induces and alters immune responses in the lung triggering inflammation, allergy, asthma and other lung diseases: a mechanistic review. Int J Environ Res Public Health. 2018;15.

23. Lugade AA, Bogner PN, Thatcher TH, Sime PJ, Phipps RP, Thanavala $Y$. Cigarette smoke exposure exacerbates lung inflammation and compromises immunity to bacterial infection. J Immunol Baltim Md. 1950;2014(192):5226-35.

24. Rosenberg SR, Kalhan R, Mannino DM. Epidemiology of chronic obstructive pulmonary disease: prevalence, morbidity, mortality, and risk factors. Semin Respir Crit Care Med. 2015;36:457-69.

25. Malhotra J, Malvezzi M, Negri E, Vecchia CL, Boffetta P. Risk factors for lung cancer worldwide. Eur Respir J. 2016:48:889-902.

26. Coussens LM, Werb Z. Inflammation and cancer. Nature. 2002:420:860-7.

\section{Publisher's Note}

Springer Nature remains neutral with regard to jurisdictional claims in published maps and institutional affiliations.

Ready to submit your research? Choose BMC and benefit from

- fast, convenient online submission

- thorough peer review by experienced researchers in your field

- rapid publication on acceptance

- support for research data, including large and complex data types

- gold Open Access which fosters wider collaboration and increased citations

- maximum visibility for your research: over 100M website views per year

At BMC, research is always in progress.

Learn more biomedcentral.com/submissions 